\title{
Severe and near-fatal anaphylactic reactions triggered by chlorhexidine-coated catheters in patients undergoing renal allograft surgery: a case series \\ Réactions anaphylactiques sévères et quasi fatales déclenchées par des cathéters enduits de chlorhexidine chez des patients subissant une chirurgie d'allogreffe rénale : une série de cas
}

\author{
Alex Ho, MD • Jeffrey Zaltzman, MD • Gregory M. T. Hare, MD, PhD • Lucy Chen, RPh • \\ Lisa Fu, MD • Susan M. Tarlo, MBBS • Peter Vadas, MD, PhD
}

Received: 27 January 2019/Revised: 4 May 2019/Accepted: 6 May 2019/Published online: 1 July 2019

(C) Canadian Anesthesiologists' Society 2019

\begin{abstract}
Purpose Although intraoperative anaphylaxis during surgery is a rare event, we describe five patients who experienced perioperative anaphylactic reactions during renal transplantation and were referred for investigation.

Clinical features Skin-prick and intradermal skin tests were done to investigate potential allergies to drugs given perioperatively prior to the development of anaphylaxis, including basiliximab, propofol, cefazolin, cis-atracurium, fentanyl, latex, remifentanil, and chlorhexidine. In addition, in vitro serologic testing for specific IgE was done in patients suspected to have had chlorhexidine anaphylaxis. All five patients were male, with a mean age of $48 \mathrm{yr}$ (range 30-69). Skin testing for all drugs was nonreactive except for chlorhexidine, which was positive in four of five patients (one patient refused intradermal
\end{abstract}

A. Ho, MD - G. M. T. Hare, MD, PhD

Department of Anesthesia, St. Michael's Hospital, University of Toronto, Toronto, ON, Canada

J. Zaltzman, MD · L. Chen, RPh

Division of Nephrology, Department of Medicine, St. Michael's Hospital, University of Toronto, Toronto, ON, Canada

L. Fu, MD $\cdot$ P. Vadas, MD, PhD (ه)

Division of Allergy and Clinical Immunology, Department of

Medicine, St. Michael's Hospital, University of Toronto,

Toronto, ON, Canada

e-mail:vadasp@smh.ca

S. M. Tarlo, MBBS

Division of Respirology, Department of Medicine, University Health Network, University of Toronto, Toronto, ON, Canada testing). In vitro test results for chlorhexidine-specific IgE were positive in all of the patients. Anesthetic records showed that intraoperative anaphylaxis had occurred immediately after insertion of a chlorhexidine-coated central venous catheter.

Conclusions Intraoperative insertion of chlorhexidinecoated central venous catheters can trigger lifethreatening anaphylaxis in susceptible patients undergoing renal transplantation.

\section{Résumé}

Objectif Bien que l'anaphylaxie peropératoire pendant la chirurgie soit une complication rare, nous décrivons ici les cas de cinq patients ayant subi des réactions anaphylactiques périopératoires pendant une greffe rénale et qui ont été référés pour examens approfondis. Éléments cliniques Des tests par scarification et des tests intradermiques ont été réalisés afin d'évaluer les allergies potentielles aux médicaments administrés en période périopératoire avant l'apparition de l'anaphylaxie, notamment la sensibilité des patients au basiliximab, au propofol, à la céfazoline, au cisatracurium, au fentanyl, au latex, au rémifentanil et à la chlorhexidine. En outre, des tests sérologiques in vitro ont été réalisés pour l'immunoglobuline E (IgE) spécifique chez les patients soupçonnés d'avoir souffert d'un choc anaphylactique à la chlorhexidine. Les cinq patients étaient tous des hommes, d'un âge moyen de 48 ans (30 à 69 ans). Les tests dermiques étaient non réactifs pour tous les médicaments à l'exception de la chlorhexidine, pour laquelle le test s'est révélé positif chez quatre des cinq patients (un patient a refusé le test intradermique). Les résultats des tests in vitro 
pour l'IgE spécifique à la chlorhexidine étaient positifs chez tous les patients. Les dossiers anesthésiques ont montré que l'anaphylaxie peropératoire était survenue immédiatement après l'insertion d'un cathéter veineux central enduit de chlorhexidine.

Conclusion L'insertion peropératoire de cathéters veineux centraux enduits de chlorhexidine peut déclencher une anaphylaxie potentiellement fatale chez les patients susceptibles subissant une greffe rénale.

Chlorhexidine (CHX) is a highly effective antimicrobial agent that is routinely used in the perioperative setting as a skin antiseptic. With widespread use, allergic reactions have been reported, including contact dermatitis, fixeddrug eruptions, asthma, and life-threatening anaphylaxis. ${ }^{1}$ Chlorhexidine-coated medical devices have also become increasingly popular, based on evidence of a reduction in the risk of bacterial colonization and infection.

Previous studies have shown that patients may become sensitized to CHX through repeated exposures to antiseptic skin preparations, oral rinses, topical washes, and wound dressings. As a result of repeated CHX exposure, some patient populations may be at increased risk for sensitization and anaphylaxis. For example, patients undergoing bladder catheterization are at risk of sensitization because CHX is present in the urologic gels used for catheter insertion. Re-exposure to CHX in these patients may then cause anaphylaxis. Prior to undergoing renal allograft surgery, patients with end-stage renal disease are routinely exposed to CHX to disinfect arteriovenous fistulae before hemodialysis. Repeated epicutaneous exposure has been reported to increase the risk of allergic sensitization to $\mathrm{CHX}^{2,3}$ Consequently, patients on hemodialysis may require either strict avoidance of perioperative $\mathrm{CHX}$ exposure or extensive pre-screening prior to surgery to identify those patients at high risk of potentially fatal perioperative anaphylaxis.

Herein, we describe five patients who experienced severe or near-fatal anaphylaxis during renal allograft surgery immediately following placement of CHX-coated central venous catheters (CVL). This report was undertaken with approval of the St. Michael's Hospital research ethics board (approval no. 19-105; April 22, 2019).

These patients were referred to the Allergy and Clinical Immunology service in a tertiary care university teaching hospital for investigation of severe intraoperative anaphylaxis. Serologic testing was undertaken for chlorhexidine-specific IgE using ImmunoCAP testing (Thermo Fisher Scientific; Waltham, MA, USA). ${ }^{4-6} \mathrm{~A}$ positive ImmunoCAP test was defined as $>0.35 \mathrm{kUA} \cdot \mathrm{L}^{-1}$ (kilounits of antibody per litre). Dexidin 2 Solution ( (chlorhexidine 2\%, 3M London, ON, Canada) was used for skin testing at serial ten-fold dilutions. Skin-prick testing was performed and if results were negative, intradermal tests were performed. A positive skin test result was defined as a skin-wheal diameter that was $3 \mathrm{~mm}$ greater than that of saline controls. Appropriate positive (histamine) and negative ( $0.9 \%$ saline) controls were obtained. Skin and serologic tests were deferred for a minimum of six weeks following the anaphylactic reaction. Serum tryptase levels were obtained within $90 \mathrm{~min}$ of onset of anaphylaxis in three patients.

\section{Case 1}

This 63-yr-old male with end-stage renal disease (ESRD) secondary to hypertension and type-II diabetes presented for renal transplantation in 2008. He had been on hemodialysis via an arterio-venous (AV) arm fistula for six years. At that initial transplant operation, he received basiliximab pre-treatment followed by induction of anesthesia using midazolam, fentanyl, propofol, and rocuronium. Shortly after CVL placement, the patient developed profound hypotension that progressed to a pulseless electrical activity (PEA) cardiac arrest with a narrow complex tachycardia and ST-segment depression; the operation was cancelled. Allergy skin tests to cefazolin, rocuronium, and latex gave negative results as did ImmunoCAP testing for latex-specific IgE. Basiliximab could not be obtained for skin testing and CHX testing was also not performed.

Transplantation was attempted again in 2009 using a regimen that did not include basiliximab or cefazolin. Anesthesia was induced with midazolam, fentanyl, propofol, and rocuronium. During insertion of a CVL, he developed wheezing and hypotension that progressed to PEA with a narrow complex tachycardia. Subsequent allergy testing to fentanyl, midazolam, and propofol gave negative results. Repeat cardiology evaluation directed toward dynamic outflow tract obstruction was noncontributory. Although there were suggestions that these PEA events were allergic in nature, a specific allergen was not identified. Serum tryptase was not measured.

The patient was again re-scheduled for transplantation in 2011 with a plan to avoid agents to which the patient had previously been exposed, including latex, propofol, fentanyl, rocuronium, cefazolin, and basiliximab. He received thiopental, remifentanil, and cis-atracurium to induce general anesthesia. Approximately five to ten minutes following CVL insertion, the patient developed increased airway pressures followed by hypotension and 
then PEA/ventricular tachycardia arrest. Serum tryptase was elevated $40 \mathrm{~min}$ after the arrest at $200 \mu \mathrm{g} \cdot \mathrm{L}^{-1}$ (a normal level is $<11.4 \mu \mathrm{g} \cdot \mathrm{L}^{-1}$ ).

Although an allergic reaction was suspected even after the patient's first PEA arrest, repeated testing gave inconclusive results. Given that the reactions occurred temporally following CVL insertion, the patient was recalled and tested for allergy to basiliximab and $\mathrm{CHX}$ in 2015. The latter gave a positive skin test result and the finding was confirmed by ImmunoCAP assay for CHXspecific IgEs. The timing of the patient's multiple PEA arrests after CVL insertion and test results were consistent with the diagnosis of IgE-mediated CHX anaphylaxis. All three anaphylactic events involved skin preparation with CHX preceding insertion of a CHX-coated ARROWg+ard Blue PLUS ${ }^{2}$ CVL (Teleflex Incorporated, Wayne, PA, USA). In 2016, this patient underwent uneventful transapical aortic valve replacement for aortic stenosis where CHX exposure was strictly avoided during the procedure.

\section{Case 2}

A 30-yr-old male with idiopathic ESRD treated with hemodialysis since 1995 presented for a cadaveric renal transplant in 2009. He was treated preoperatively with thymoglobulin, tacrolimus, and methylprednisolone, and with intravenous immunoglobulin (IVIG) infusion as part of his immunosuppression regimen. The patient underwent uneventful anesthesia induction with midazolam, propofol, fentanyl, and cis-atracurium and was maintained on desflurane with air/oxygen mixture. A CVL (ARROWg+ard Blue PLUS®) was inserted in the internal jugular vein. Shortly afterwards, the patient's peak airway pressures increased to $32 / 5 \mathrm{cmH}_{2} \mathrm{O}$ and his $\mathrm{O}_{2}$ saturation fell to $92 \%$. Systolic blood pressure transiently decreased from 120 to $100 \mathrm{mmHg}$ and there was an increase in heart rate to $70-90$ beats $\cdot \mathrm{min}^{-1}$. A red rash was noted on his chest. The transplantation procedure was completed without further incident. Serum tryptase was not measured.

The patient had an uneventful postoperative course. His intraoperative event was considered mild and attributed to the IVIG he received. His presentation was identified through chart review and the patient was referred for allergy evaluation seven years after his transplant. He was found to have a positive intradermal skin test result for $\mathrm{CHX}$ and a positive ImmunoCAP result for $\mathrm{CHX}$-specific IgE.

\section{Case 3}

This 41-yr-old male with ESRD secondary to type-II diabetes presented for transplantation in 2012. He had a previously documented remote urticarial reaction to $\mathrm{CHX}$. Cefazolin and basilixmab were administered preoperatively. Anesthesia was induced with fentanyl, propofol, and rocuronium. Shortly after CVL insertion, the patient developed bronchospasm, tachycardia, hypotension, and a generalized rash, which resolved with the administration of phenylephrine, diphenhydramine, and ranitidine. The transplantation procedure was completed without further incident. Serum tryptase was not measured.

As with case 2 above, this patient was identified after a chart review and he was referred for allergy evaluation four years after renal transplant. Operating room records revealed that his CVL insertion site was prepared with iodine-based disinfectant, not CHX. Nevertheless, the CVL used was also a CHX-coated ARROWg+ard Blue PLUS®. Both skin testing and ImmunoCAP testing for specific IgE confirmed sensitization to $\mathrm{CHX}$.

\section{Case 4}

This 69-yr-old male with ESRD secondary to hypertension and type-I diabetes presented for transplantation in 2015. He received cefazolin, methylprednisolone, and basiliximab preoperatively and anesthesia was induced with remifentanil, fentanyl, propofol, and cis-atracurium. Immediately following insertion of a CHX-coated ARROWg+ard Blue PLUS $®$ CVL, the patient developed hypotension and increased airway pressure, which responded to epinephrine, norepinephrine, dobutamine, and calcium gluconate. Serum tryptase was markedly elevated two hours after the event $\left(101 \mu \mathrm{g} \cdot \mathrm{L}^{-1}\right)$. Subsequent allergy testing revealed negative skin test results to basilixmab and other drugs given pre- and intraoperatively whereas skin test results and ImmunoCAP for specific IgEs to $\mathrm{CHX}$ were positive.

\section{Case 5}

This 37-yr-old male with ESRD secondary to focal segmental glomerulosclerosis presented for transplantation. He received cefazolin, methylprednisolone, and basiliximab preoperatively and was induced with remifentanil, fentanyl, propofol, and rocuronium. Profound hypotension immediately after placement of a CHX-coated CVL (ARROWg+ard Blue PLUS $\AA$ ) progressed to PEA arrest, which was treated with an epinephrine infusion, hydrocortisone, and calcium 
gluconate. Serum tryptase was elevated $15 \mathrm{hr}$ after the event $\left(31.6 \mu \mathrm{g} \cdot \mathrm{L}^{-1}\right)$. Allergy assessment revealed a long history of pruritic cutaneous reactions following application of CHX to his AV fistula site during hemodialysis. Both skin test results and ImmunoCAP test results for CHX-specific IgEs were positive. $\mathrm{He}$ subsequently underwent successful renal transplantation during which CHX exposure was strictly avoided.

\section{Discussion}

We report five patients who were referred for investigation of intraoperative anaphylaxis occurring during renal allograft surgery during the years 2009-2015. Patient demographics, co-morbidities, manifestations, and anaphylaxis severity grade are shown in the Table. The mean age at time of perioperative anaphylaxis was $48 \mathrm{yr}$ (range, 30-69 yr). All patients were male. The patients developed severe anaphylaxis under general anesthesia immediately after insertion of CHX-coated CVL with two experiencing perioperative cardiac arrest (i.e., PEA). All five patients experienced grade 3 (severe) reactions as defined by Brown et al. ${ }^{7}$ Post-anaphylaxis tryptase levels measured in three of the patients were markedly elevated. Patients underwent allergy testing for all drugs given prior to anaphylaxis. Upon reviewing the anesthesia records, it was noted that all five patients developed severe anaphylaxis immediately after insertion of the same CHX-coated CVL (ARROWg+ard Blue PLUS ${ }^{\circledR}$, Arrow International) in preparation for renal transplantation. Four of five patients subsequently tested positive for CHX allergy by skin-prick or intradermal testing and all $5 / 5$ tested positive for $\mathrm{CHX}$-specific IgEs by ImmunoCAP testing.

Chlorhexidine is routinely used as an antiseptic to disinfect skin prior to venipuncture or surgery.
Chlorhexidine derivatives form protein conjugates via nucleophilic groups on methionine, tyrosine, lysine, and tryptophan residues. ${ }^{8}$ The resultant allergenic hapten stimulates production of allergen-specific IgEs. In studies of the IgE-binding epitopes on CHX, the parent molecule itself is highly immunogenic. The structural region responsible for high affinity binding is the hexamethylene biguanide moiety in CHX, which is also found in polyhexanide. ${ }^{9}$ Polyhexanide, a CHX-derived polymer, is widely used as a surgical field disinfectant, and radioallergosorbent-inhibition studies have shown crossreactivity in vitro between $\mathrm{CHX}$ and polyhexanide. Patients sensitized to CHX have experienced anaphylaxis upon exposure to polyhexanide. ${ }^{9}$ Interestingly, the oral hypoglycemic agent metformin also contains a biguanide moiety, and has been postulated, although not proven, to result in sensitization to $\mathrm{CHX} .^{9}$ Nevertheless, in patients sensitized to CHX, re-exposure by cutaneous, mucosal, or parenteral routes may result in severe anaphylaxis. A number of products containing CHX may predispose to allergic sensitization, including antiseptic skin preparations, oral rinses, topical washes, and wound dressings. Patients undergoing urologic procedures have also been reported to be at risk for anaphylaxis because of the presence of CHX in the urologic gels used for catheter insertion. $^{10-15}$

In patients with ESRD, CHX is routinely used to disinfect AV fistulae before hemodialysis. IgE-mediated sensitization has been reported as a result of insertion of intravenous cannulas through CHX-treated skin. ${ }^{2}$ The routine use of CHX to disinfect $\mathrm{AV}$ fistulae for hemodialysis may potentially lead to allergic sensitization, increasing the risk of anaphylaxis upon insertion of CHX-coated catheters.

Chlorhexidine-coated CVL were introduced into clinical practice based on evidence that these devices were less likely to be colonized with bacteria at the time of removal

Table Clinical characteristics of five patients with anaphylactic reactions to CHX- coated catheters

\begin{tabular}{|c|c|c|c|c|c|c|c|c|}
\hline $\begin{array}{l}\text { Patient } \\
\#\end{array}$ & Gender & $\begin{array}{l}\text { Age at } \\
\text { reaction }\end{array}$ & Co-morbidities & Procedure & Type of reaction & $\begin{array}{l}\text { Reaction } \\
\text { severity }\end{array}$ & $\begin{array}{l}\text { Tryptase } \\
\left(\mu \mathrm{g} \cdot \mathrm{L}^{-1}\right)\end{array}$ & $\begin{array}{l}\text { Chlorhexidine- } \\
\text { specific IgE }\end{array}$ \\
\hline 1 & M & 63 & HTN, DM2 & Renal Tx & PEA cardiac arrest & 3 & $200 \mu \mathrm{g} \cdot \mathrm{L}^{-1}$ & $3.93 \mathrm{kUA} \cdot \mathrm{L}^{-1}$ \\
\hline 2 & M & 30 & Idiopathic ESRD & Renal TX & $\begin{array}{l}\text { Hypotension, increased airway } \\
\text { pressure, rash }\end{array}$ & 3 & ND & $0.63 \mathrm{kUA} \cdot \mathrm{L}^{-1}$ \\
\hline 3 & M & 41 & DM2 & Renal Tx & $\begin{array}{l}\text { Hypotension, tachycardia, } \\
\text { bronchospasm, rash }\end{array}$ & 3 & ND & $2.63 \mathrm{kUA} \cdot \mathrm{L}^{-1}$ \\
\hline 4 & M & 69 & $\begin{array}{l}\text { DLP, OSA, DM2, } \\
\text { MI, HTN }\end{array}$ & Renal Tx & $\begin{array}{l}\text { Hypotension, increased airway } \\
\text { pressure }\end{array}$ & 3 & 101 & $1.54 \mathrm{kUA} \cdot \mathrm{L}^{-1}$ \\
\hline 5 & M & 37 & HTN & Renal Tx & PEA cardiac arrest & 3 & 31.6 & $0.54 \mathrm{kUA} \cdot \mathrm{L}^{-1}$ \\
\hline
\end{tabular}

$\mathrm{CHX}=$ chlorhexidine; DLP = dyslipidemia; DM2 = type 2 diabetes mellitus; Hep B = hepatitis B; Hep C = hepatitis C; HTN = hypertension; MI $=$ myocardial infarction; $\mathrm{ND}=$ not done; $\mathrm{OA}=$ osteoarthritis; OSA = obstructive sleep apnea; $\mathrm{PEA}=$ pulseless electrical activity; Tx = transplant 
compared with control catheters. ${ }^{16}$ Catheter-related bloodstream infection was 0.42 per 1,000 catheter-days for antiseptic coated catheters compared with 1.24 per 1,000 catheter-days for the control group. ${ }^{17}$ In a Cochrane systematic review and network meta-analysis, CHX-silver sulfadiazine-impregnated catheters were associated with significant decreases in catheter colonization. ${ }^{17}$ Because of the reduction in the frequency of catheter-related sepsis and associated cost savings, these devices are increasingly being used in surgical and critical care settings. Nevertheless, following reports from Japan of severe and fatal systemic hypersensitivity reactions to CVL impregnated with $\mathrm{CHX}$, the manufacturer voluntarily withdrew the product from the Japanese market on 19 August 1997 (DRS Alert No. 62: Central venous catheters recalled: anaphylactic shock [ArrowguardR: Arrow], 15 September 1997). ${ }^{18}$

Since the introduction of CHX-coated CVL, there have been more than 20 case reports of anaphylaxis. ${ }^{11,19-30}$ Nevertheless, none of the reported cases involved patients undergoing renal transplantation surgery. Although $\mathrm{CHX}$ remains a relatively uncommon cause of perioperative anaphylaxis, patients with ESRD may be at increased risk of developing this allergy as a result of repetitive epicutaneous exposure to AV fistulae in preparation for hemodialysis. As our hospital is a designated regional site for renal transplantation with referrals from more than 20 institutions across the province, we find it impractical to pre-screen and test these patients before elective surgery to identify those patients who should not be exposed to CHX. Instead, we have implemented a policy of strict avoidance of perioperative $\mathrm{CHX}$ exposure in patients undergoing renal transplantation and since have had no further instances of related anaphylaxis.

Conflicts of interest None declared.

Editorial responsibility This submission was handled by Dr. Hilary P. Grocott, Editor-in-Chief, Canadian Journal of Anesthesia.

\begin{abstract}
Author contributions Alex Ho was involved in data acquisition and analysis, and study design. Lisa $F u$ was involved in the initial drafting of the manuscript. Jeffrey Zaltzman was involved in data collection. Lucy Chen was involved in data collection. Susan M. Tarlo contributed to manuscript preparation. Gregory M.T. Hare contributed to manuscript preparation. Peter Vadas was involved in data collection and analysis, study design, and preparation of the manuscript.
\end{abstract}

Funding Self-funded.

\section{References}

1. Rutkowski K, Wagner A. Chlorhexidine: a new latex? Eur Urol 2015; 68: 345-7.
2. Bahal S, Sharma S, Garvey LH, Nagendran V. Anaphylaxis after disinfection with $2 \%$ chlorhexidine wand applicator. BMJ Case Rep 2017; DOI: https://doi.org/10.1136/bcr-2017-219794.

3. Kallen AJ, Patel PR, Hess S. Intolerance of chlorhexidine as a skin antiseptic in patients undergoing hemodialysis. Infect Control Hosp Epidemiol 2011; 32: 1144-6.

4. Anderson J, Rose M, Green S, Fernando SL. The utility of specific $\operatorname{IgE}$ testing to chlorhexidine in the investigation of perioperative adverse reactions. Ann Allergy Asthma Immunol 2015; 114(425-6): e1.

5. Senna $G$, Bonadonna $P$, Caruso $B$, et al. Skin test and specific IgE predictive value on the chlorhexidine allergy. J Allergy Clin Immunol 2011; 127: AB198.

6. Opstrup MS, Poulsen LK, Malling HJ, Jensen BM, Garvey LH. Dynamics of plasma levels of specific $\operatorname{IgE}$ in chlorhexidine allergic patients with and without accidental re-exposure. Clin Exp Allergy 2016; 46: 1090-8.

7. Brown SG. Clinical features and severity grading of anaphylaxis. J Allergy Clin Immunol 2004; 114: 371-6.

8. Layton GT, Stanworth DR, Amos HE. The specificity of murine polyclonal and monoclonal antibodies to the haptenic drug chlorhexidine induced by chlorine-generated chlorhexidine protein conjugates. Clin Exp Immunol 1987; 69: 157-65.

9. Calogiuri GF, Di Leo E, Trautmann A, Ferrannini A, Vacca A. Chlorhexidine hypersensitivity: a critical and updated review. J Allergy Ther 2013; DOI: https://doi.org/10.4172/2155-6121. 1000141.

10. Buergi A, Jung B, Padevit C, John H, Ganter MT. Severe anaphylaxis: the secret ingredient. A A Case Rep 2014; 2: 34-6.

11. Sharp G, Green $S$, Rose M. Chlorhexidine-induced anaphylaxis in surgical patients: a review of the literature. ANZ J Surg 2016; 86: 237-43.

12. Nakonechna $A$, Dore $P$, Dixon $T$, et al. Immediate hypersensitivity to chlorhexidine is increasingly recognised in the United Kingdom. Allergol Immunopathol (Madr) 2014; 42: 44-9.

13. Parkes AW, Harper N, Herwadkar A, Pumphrey R. Anaphylaxis to the chlorhexidine component of Instillagel: a case series. $\mathrm{Br} \mathbf{J}$ Anaesth 2009; 102: 65-8.

14. Jayathillake A, Mason DF, Broome K. Allergy to chlorhexidine gluconate in urethral gel: report of four cases and review of the literature. Urology 2003; 61: 837.

15. Stewart $M$, Lenaghan $D$. The danger of chlorhexidine in lignocaine gel: a case report of anaphylaxis during urinary catheterisation. Australas Med J 2015; 8: 304-6.

16. Rupp ME, Lisco SJ, Lipsett PA, et al. Effect of a secondgeneration venous catheter impregnated with chlorhexidine and silver sulfadiazine on central catheter-related infections: a randomized, controlled trial. Ann Intern Med 2005; 143: 570-80.

17. Chong HY, Lai NM, Apisarnthanarak A, Chaiyakunapruk $N$. Comparative efficacy of antimicrobial central venous catheters in reducing catheter-related bloodstream infections in adults: abridged Cochrane systematic review and network metaanalysis. Clin Infect Dis 2017; 64(supp12): S131-40.

18. World Health Organization. Chlorhexidine-impregnated medical devices - hypersensitivity reactions. WHO Pharmaceuticals Newsletter 1998; No. 03\&04. Available from URL: http://apps. who.int/medicinedocs/en/d/Js2256e/5.html (accessed May 2019).

19. Wang ML, Chang CT, Huang HH, Yeh YC, Lee TS, Hung KY. Chlorhexidine-related refractory anaphylactic shock: a case successfully resuscitated with extracorporeal membrane oxygenation. J Clin Anesth 2016; 34: 654-7.

20. Qin Z, Zeng Z. Anaphylaxis to chlorhexidine in a chlorhexidinecoated central venous catheter during general anaesthesia. Anaesth Intensive Care 2016; 44: 297-8. 
21. Weng $M$, Zhu $M$, Chen $W$, Miao $C$. Life-threatening anaphylactic shock due to chlorhexidine on the central venous catheter: a case series. Int J Clin Exp Med 2014; 7: 5930-6.

22. Zheng $X$, Fang $X$, Cai $X$. Two episodes of anaphylaxis caused by a chlorhexidine sulfadiazine-coated central venous catheter. Chin Med J (Engl) 2014; 127: 2395-7.

23. Toomey $M$. Preoperative chlorhexidine anaphylaxis in a patient scheduled for coronary artery bypass graft: a case report. AANA J 2013; 81: 209-14.

24. Guleri A, Kumar A, Morgan RJ, Hartley M, Roberts DH. Anaphylaxis to chlorhexidine-coated central venous catheters: a case series and review of the literature. Surg Infect (Larchmt) 2012; 13: 171-4.

25. Faber M, Leysen J, Bridts C, Sabato V, De Clerck LS, Ebo DG. Allergy to chlorhexidine: beware of the central venous catheter. Acta Anaesthesiol Belg 2012; 63: 191-4.

26. Khoo A, Oziemski P. Chlorhexidine impregnated central venous catheter inducing an anaphylactic shock in the intensive care unit. Heart Lung Circ 2011; 20: 669-70.
27. Jee $R$, Nel L, Gnanakumaran $G$, Williams A, Eren E. Four cases of anaphylaxis to chlorhexidine impregnated central venous catheters: a case cluster or the tip of the iceberg? Br J Anaesth 2009; 103: 614-5.

28. Kluger $M$. Anaphylaxis to chlorhexidine-impregnated central venous catheter. Anaesth Intensive Care 2003; 31: 697-8.

29. Pittaway A, Ford S. Allergy to chlorhexidine-coated central venous catheters revisited. Br J Anaesth 2002; 88: 304-5.

30. Stephens $R$, Mythen $M$, Kallis $P$, Davies DW, Egner W, Rickards $A$. Two episodes of life-threatening anaphylaxis in the same patient to a chlorhexidine-sulphadiazine-coated central venous catheter. Br J Anaesth 2001; 87: 306-8.

Publisher's Note Springer Nature remains neutral with regard to jurisdictional claims in published maps and institutional affiliations. 